\title{
Correction to: Modeling complex network patterns in international trade
}

\author{
Peter R. Herman ${ }^{1} \mathbb{D}$
}

Published online: 4 October 2021

(c) Kiel Institute 2021

\section{Correction to: Review of World Economics https://doi.org/10.1007/s10290-021-00429-y}

In the original publication of the article, two figures which were mentioned in the third paragraph of the introduction section below are missed in the article.

To illustrate the notion of complex network patterns in international trade, Fig. 1 depicts the trade flows between the United States (USA), El Salvador (SLV), Trinidad and Tobago (TTO), Bolivia (BOL), and Nepal (NPL) in 1999 as a network. A link pointing from one country to another indicates that the originating country exported to the destination country. Consider the exports from El Salvador to Trinidad and Tobago (drawn in red). A typical trade model, such as a gravity equation, will model that trade flow as being dependent on certain unilateral characteristics of the two countries, such as their GDPs or MFN tariffs (or, more commonly, via country fixed effects), and bilateral characteristics, such as the distances between the markets or their preferential trade arrangements. However, there are other relationships in the network that might also affect this trade flow. For example, Trinidad and Tobago export to El Salvador, implying that their trade is reciprocal. Similarly, both countries have multiple other import and export partners, which may create network externalities in both markets. Finally, both countries trade with common third parties, such as the United States, which might impact trade though things like supply chains or information spillovers. Network relationships are even more prevalent and extensive when considering the full world trade network, as is presented in Fig. 2.

The original article can be found online at https://doi.org/10.1007/s10290-021-00429-y.

Peter R. Herman

Peter.Herman@usitc.gov

1 Office of Economics, U.S. International Trade Commission, Washington, DC, USA 


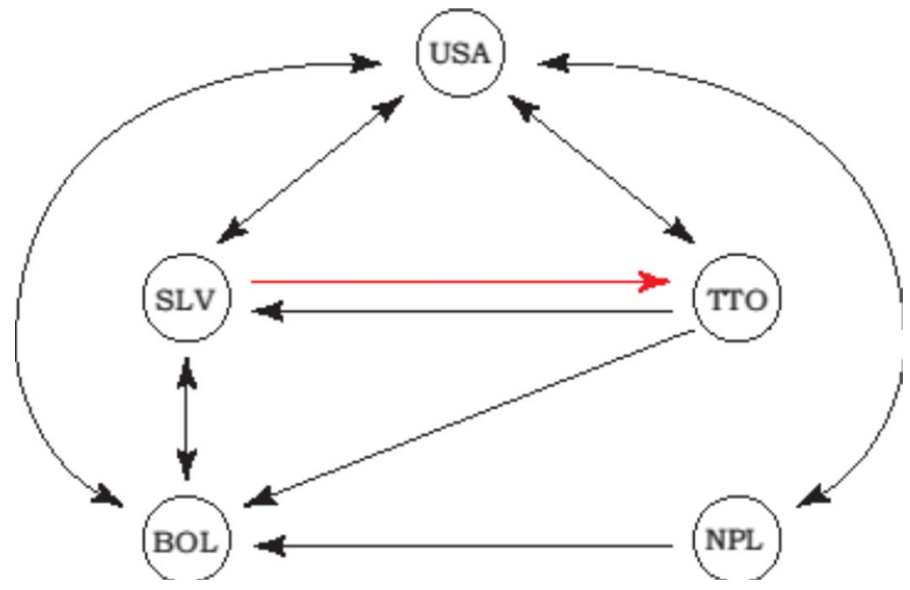

Fig. 1 Trade ows between the United States (USA), El Salvador (SLV), Trinidad and Tobago(TTO), Bolivia (BOL), and Nepal (NPL) in 1999

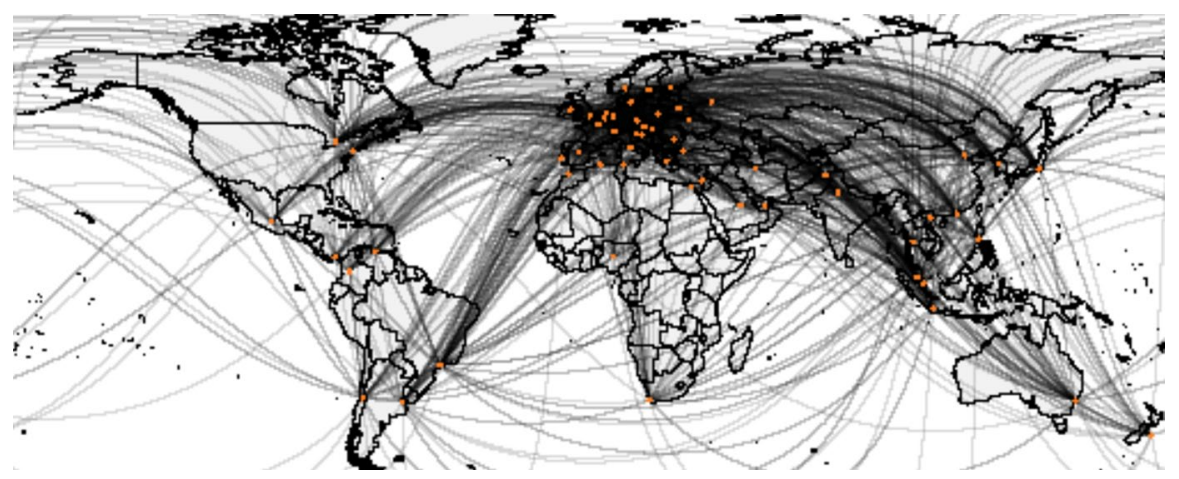

Fig. 2 The World Trade Network (2006)

Publisher's Note Springer Nature remains neutral with regard to jurisdictional claims in published maps and institutional affiliations. 